\title{
Penerapan Metode Kauny Quantum Memory dalam Meningkatkan Hafalan dan Pemahaman Siswa Pada Pembelajaran Tahfiz di MI Nurul Qomar Palembang
}

\author{
Dini Febriani Sidauruk ${ }^{1^{*}}$ \\ ${ }^{1 *}$ Universitas Islam Negeri Raden Fatah, Palembang, Indonesia \\ dinifebriani1234@gmail.com
}

\begin{abstract}
The problems that occur in Tahfiz learning at MI Nurul Qomar are memorization and students' understanding in the memorization process is still low, so we need a method that allows students to memorize. The purpose of this study was to improve students' memorization and understanding of the Kauny Quantum Memory method in the process of learning to memorize students at MI Nurul Qomar Palembang. This type of research is field research using quantitative research approaches and the design used is quasi-experimental. Data collection is done by oral tests, interviews, observations, and documentation, data analysis using $T$ tests. The findings in this study are that learning Tahfiz in MI Nurul Qomar Palembang by applying the Kauny Quantum Memory method has a significant effect. This is evidenced by the hypothesis test that uses the t test, the value of $t_{-}$count is obtained $=4.112$ while ttable $=2.09$. Therefore it can be concluded that $t$ count $>$ $t_{-}$table or 4,112> 2.09. Because t_calculate $=4.112$ is greater than the price of ttable $=2.09$ at a significant level of 5\% with degrees of freedom n-2 $(22-2=20)$. So $H_{-} o$ which states there is no significant influence with the application of the Kauny Quantum Memory method in improving students 'memorization and understanding in Tahfiz learning at MI Nurul Qomar Palembang is rejected, while $H \_a$ which states there is a significant influence with the application of the Kauny Quantum Memory method in improving students' memorization and understanding in Tahfiz learning at MI Nurul Qomar Palembang is accepted. So, the Kauny Quantum Memory learning method can be said as one of the effective learning methods to improve memorization and understanding of the Koran of students at MI Nurul Qomar Palembang.
\end{abstract}

Keywords : Method of Kauny Quantum Memory, Memorization and Understanding of the AlQur'an.

\section{INFORMASI ARTIKEL}

Submitted, August 16, 2019

Revised, October 17, 2019

Accepted, December 14, 2019 


\section{PENDAHULUAN}

Pendidikan anak usia dini merupakan bagian dari pencapaian tujuan yaitu bertujuan untuk berkembangnya potensi peserta didik agar menjadi manusia yang beriman dan bertaqwa kepada Tuhan yang Maha Esa, beraklak mulia, sehat, berilmu, cakap, kreatif, mandiri, dan menjadi warga negara yang demokratis serta bertanggung jawab. Tujuan pendidikan nasional pada dasarnya adalah mencetak generasi manusia yang beriman dan bertaqwa kepada Tuhan yang Maha Esa. Salah satu cara yang dapat dilakukan adalah dengan memperkenalkan AlQur'an pada anak sejak usia dini. Setiap orang yang beragama Islam harus dapat menghafal ayat-ayat Al-Qur'an, sekurang-kurangnya sebagian dari surat-surat pendek Al-Qur'an yang terhimpun dalam Juz 'Amma yaitu juz ke 30 dalam Al-Qur'an karena surah-surah tersebut merupakan bacaan yang akan digunakan dalam sholat.

Al-Qur'an merupakan kalam Allah SWT dan sekaligus mukjizat yang agung dan kekal, mu'jizat bagi Rasulullah SAW yang selalu dijaga kesuciannya langsung oleh Allah SWT dari segala penyimpangan dan perubahan, tidak seperti kitab-kitab lainnya (Ahmad, 1992). Mempunyai hafalan Al-Qur'an atau penghafal Al-Qur'an merupakan sebuah keistimewaan yang diberikan oleh Allah SWT dari pada manusia lainnya, yaitu anugrah dalam menjaga kemurnian Al-Qur'an, keistimewaan lain yaitu merupakan keluarga Allah SWT di muka bumi. Apalagi jika kecintaannya dalam menghafal Al-Qur'an sudah ditanamkan kepada anak sejak usia dini, maka hal itu akan membuatnya semakin terbiasa dan semakin terasah dalam menghafal Al-Qur'an ketika dewasa (Al-Hafidz, 1994). Proses pembiasaan menghafal sejak usia kecil akan menjadikan anak tersebut semakin mudah menghafal Al-Qur'an di usia dewasa, seperti dikutip dalam hadis yang diriwayatkan oleh Bukhari (Sa'dulloh, 2008) yang berbunyi "Barang siapa yang mempelajari Al-Qur'an di usia kecil, maka Allah SWT akan mencampurkan (Al-Qur'an) dengan daging dan darahnya".

Menurut Thorndike (Djiwandono, 2002) prinsip belajar law exercise (hukum latihan) yaitu hubungan antara stimulus dan respon akan semakin kuat, dengan banyaknya respon yang dilaksanakan terhadap stimulus. Maka dengan banyak latihan yang dilakukan selama masa kecil akan semakin meningkatkan kemampuan menghafalnya. Dan akan semakin mempererat interaksi dirinya dengan Al-Qur'an dan akan menjadikan hafalannya semakin kuat di masa dewasanya. Perkembangan kognitif pada peserta didik sekolah dasar (SD) memiliki rasa ingin tahu yang tinggi dan ingin belajar. Namun, sebagian besar anak pada masa ini belum mampu memahami konsep-konsep abstrak. Masa ini disifatkan sebagai masa realisme, yaitu realisme naif (umur 8 sampai 10 tahun) dan realisme kritis (umur 10 sampai 12 tahun). Adanya perhatian kepada kehidupan yang praktis dan konkret tersebut membawa kecenderungan untuk membantu pekerjaan-pekerjaan yang praktis (Nazarudin, 2013).

Menghafal Al-Qur'an perlu disimpan secara baik, karena wajib diaplikasikan seumur hidup. Oleh karena itu penghafalan Al-Qur'an memerlukan penyimpanan informasi yang baik yaitu penyimpanan jangka panjang, karena dapat diakses kapanpun dan dimanapun. Proses penyimpanannya didahului dengan penyandian dengan prinsip-prinsip tertentu. Agar materi pelajaran dapat tersimpan dalam memori jangka panjang. Maka diperlukan suatu strategi penyimpanan informasi yang sesuai dengan prinsip-prinsip penyandian dalam memori jangka panjang. Menurut Wiwi Alawiyah Wahid, ada tiga tahapan tentang ingatan seseorang, sebagaimana berikut: memasukan informasi kedalam ingatan, penyimpanan informasi atau materi ke dalam memori dan pengungkapan kembali (Wiwi, 2015).

Memori dibedakan atas memori jangka pendek (Short term memory) dan memori jangka panjang (long term memory). Memori jangka pendek (Short term memory) merupakan suatu tempat penyimpanan sementara. Memori ini memiliki 7 kapasitas memori dan berdurasi sekitar 15-30 detik. Sedangkan memori jangka panjang (long term memory) merupakan bagian sistem memori seseorang yang menyimpan informasi dalam periode waktu yang cukup 
lama. Informasi yang disimpan tidak ada yang hilang, baik itu karena lupa atau apapun (Abidin, 2016). Diperkuat dengan metode isyarat tangan (salah satu teknik dalam metode Kauny Quantum Memory) yang diterapkan oleh ayah Husein Tabataba'I dalam mengajarkan makna ayat-ayat Al-Qur'an pada anaknya. Sayyid Muhammad Husein Tabataba'I dari Iran merupakan doktor cilik yang menghafal seluruh isi Al-Qur'an pada usia 5 tahun, bisa menerjemahkan arti setiap ayat kedalam bahasa Persia, memahami makna ayat-ayat tersebut, dan bisa menggunakan ayat-ayat itu dalam percakapan sehari-hari (Sulaeman, 2007).

Yayasan Nurul Qomar yang memiliki program unggulan tahfidz Al-Qur'an dalam bentuk kompetensi lulusan sekolah maupun program ekstrakurikuler, memiliki perbedaan sistem metode menghafal Al-Qur'an dengan pondok pesantren yang khusus dalam bidang tahfidz Al-Qur'an. Perbedaan tersebut antara lain terdapat pada metode pembelajaran menghafal Al-Qur'an dalam segi modifikasi tempat dan waktu. Yayasan MI Nurul Qomar menyediakan asrama untuk siswa MI,dan MTS. Namun, siswa-siswa MI Nurul Qomar tidak wajib untuk menginap diasrama. Dengan demikian orang tua mempunyai peran aktig dalam membimbing anaknya menghafal dan mengulang-ulang hafalan ketika siswa pulang ke rumah masing-masing. MI Nurul Qomar Palembang merupakan lembaga pendidikan Islam tingkat sekolah dasar yang mengajarkan pentingnya menghafal. Pelajaran yang berkaitan dengan hafalan yaitu Tahfiz, dan BTA (Baca Tulis Al-Qur'an).

Menurut hasil observasi peneliti, kendala yang muncul dalam pembelajaran tahfiz di MI Nurul Qomar adalah kurangnya variasi metode menghafal yang hanya menggunakan cara belajar secara auditori saja (hanya mendengarkan dan menirukan), kurangnya minat siswa untuk menghafal, semangat siswa yang naik turun, siswa kurang konsentrasi terhadap materi hafalan, siswa lupa pada hafalan yang sudah dihafal, perbedaan cara belajar siswa, target hafalan yang tidak tercapai, kemampuan kognitif yang berbeda-beda antar individu. Adapun kendala yang dialami guru adalah tidak mampu memonitoring hafalan secara individu, metode menghafal yang monoton, dan manajemen kelas yang kurang kondusif (hasil observasi sekolah, 18 Agustus 2018).

Menurut Ibu Elly, guru tahfiz di sekolah tersebut, saat ini siswa kelas tinggi (kelas 4,5,dan 6) mengalami penuruan dalam menghafal. Ibu Elly sudah membimbing dan mengajarnya dengan metode talaqqi (membimbing siswa untuk membaca berulang-ulang, satu ayat hingga ayat berikutnya) namun siswa-siswa tersebut belum mencapai target hafalan secara sempurna. Menurutnya, kendala yang terjadi saat ini adalah banyak siswa yang mudah lupa dengan hafalan yang telah dihafal. Siswa kurang semangat dan kesulitan dalam proses menghafal di kelas. (hasil wawancara guru Tahfiz kelas 4,5,dan 6, 20 Agustus 2018).

Dari berbagai permasalahan diatas merupakan beberapa masalah yang dihadapi oleh MI Nurul Qomar Palembang. Oleh karena itu peneliti tertarik akan melakukan penelitian dengan judul tesis Penerapan Metode Kauny Quantum Memory dalam Meningkatkan Hafalan dan Pemahaman Siswa pada Pembelajaran Tahfiz di MI Nurul Qomar Palembang. Rumusan masalah penelitian ini yaitu bagaimana hafalan siswa pada pembelajaran tahfiz di MI Nurul Qomar Palembang, bagaimana pemahaman siswa pada pembelajaran tahfiz di MI Nurul Qomar Palembang dan bagaimana penerapan metode Kauny Quantum Memory dalam meningkatkan hafalan dan pemahaman siswa pada pembelajaran tahfiz di MI Nurul Qomar Palembang ? Tujuan penelitian ini adalah melihat bagaimana penerapan metode Kauny Quantum Memory dalam meningkatkan hafalan dan pemahaman siswa pada pembelajaran tahfiz di MI Nurul Qomar Palembang dan untuk menganalisa pengaruh metode Kauny Quantum Memory dalam meningkatkan hafalan dan pemahaman siswa pada pembelajaran tahfiz di MI Nurul Qomar Palembang.

Kegunaan penelitian ini secara teoritis diharapkan dapat memberikan sumbangsih bagi perkembangan dunia pendidikan Islam, dan diharapkan hasil penelitian ini nantinya bisa 
menjadi sebuah pengetahuan ilmiah dan tambahan kekayaan ilmu pengetahuan bagi insan akademik. Sedangkan untuk kegunaan Praktis bagi sekolah untuk memberikan masukan dan informasi tentang metode pembelajaran yang mendorong siswa termotivasi dalam menghafal sehingga dapat digunakan untuk kedepannya dalam pembelajaran Tahfiz. Sedangkan bagi guru, dapat menjadi acuan ataupun masukan bagi para guru untuk dapat memilih dan menerapan metode pembelajaran Kauny Quantum Memory dalam pembelajaran Tahfiz sehingga tercipta suasana yang efektif dan efisien. Dan bagi siswa dapat meningkatkan kualitas belajar dan hasil belajar siswa dalam rangka meningkatkan mutu pembelajaran

\section{METODOLOGI PENELITIAN}

Jenis penelitian yang digunakan adalah penelitian lapangan (field research), yaitu penelitian yang bertujuan untuk mengetahui pengaruh atau sebab akibat dengan cara membandingkan hasil kelompok eksperimen dan kontrol. Penelitian ini menggunakan pendekatan penelitian kuantitatif yang mana penelitian ini menganalisis menggunakan bilangan agar mengandung makna yang lebih tepat dari pada menggunakan kata-kata. Pendekatan penelitian kuantitatif didasari oleh filsafat positivisme yang menekankan fenomena-fenomena objektif dan dikaji secara kuantitatif (Sukmadinata, 2013).

Menurut Sugiyono pendekatan penelitian kuantitatif yang digunakan dalam meneliti pada populasi atau sampel tertentu, teknik pengambilan sampel pada umumnya dilakukan secara random. Desain dalam penelitian ini adalah eksperimen kuasi atau sering disebut juga eksperimen semu dengan jenis Nonequivalent Control Group Desaign artinya desain pretest dan posttest yang tidak ekuivalen (Emzir, 2014). Pada dasarnya kuasi eksperimen sama dengan eksperimen murni tetapi bedanya dalam pengontrolan variabel. Desain kuasi eksperimen hanya salah satu variabelnya dilonggarkan.

Objek penelitian ini adalah Penerapan metode Kauny Quantum Memory. Populasi penelitian ini 244 siswa dengan sampel 42 siswa. Metode pengumpulan data adalah observasi, wawancara, dokumentasi, dan tes. Adapun teknik analisis data terdiri dari uji $\mathrm{T}$, dan uji hipotesis.

Jenis penelitian yang digunakan adalah penelitian lapangan (field research), yaitu penelitian yang bertujuan untuk mengetahui pengaruh atau sebab akibat dengan cara membandingkan hasil kelompok eksperimen dan kontrol. Penelitian ini menggunakan pendekatan penelitian kuantitatif yang mana penelitian ini menganalisis menggunakan bilangan agar mengandung makna yang lebih tepat dari pada menggunakan kata-kata. Pendekatan penelitian kuantitatif didasari oleh filsafat positivisme yang menekankan fenomena-fenomena objektif dan dikaji secara kuantitatif (Sukmadinata, 2013).

Menurut Sugiyono pendekatan penelitian kuantitatif yang digunakan dalam meneliti pada populasi atau sampel tertentu, teknik pengambilan sampel pada umumnya dilakukan secara random. Desain dalam penelitian ini adalah eksperimen kuasi atau sering disebut juga eksperimen semu dengan jenis Nonequivalent Control Group Desaign artinya desain pretest dan posttest yang tidak ekuivalen (Emzir, 2014). Pada dasarnya kuasi eksperimen sama dengan eksperimen murni tetapi bedanya dalam pengontrolan variabel. Desain kuasi eksperimen hanya salah satu variabelnya dilonggarkan.

Objek penelitian ini adalah Penerapan metode Kauny Quantum Memory. Populasi penelitian ini 244 siswa dengan sampel 42 siswa. Metode pengumpulan data adalah observasi, wawancara, dokumentasi, dan tes. Adapun teknik analisis data terdiri dari uji $\mathrm{T}$, dan uji hipotesis. 


\section{HASIL DAN PEMBAHASAN}

Penelitian ini bertujuan untuk mendeskripkan pengaruh penerapan metode Kauny Quantum Memory dalam meningkatkan hafalan dan pemahaman siswa pada pembelajaran Tahfiz di MI Nurul Qomar Palembang. Penelitian ini dilaksanakan dalam 4 kali pertemuan, dengan rincian 1 kali pertemuan kelas kontrol dan 3 kali pertemuan di kelas eksperimen yang menerapkan metode Kauny Quantum Memory.

Untuk mengetahui ada atau tidaknya pengaruh penerapan metode Kauny Quantum Memory yang signifikan dalam meningkatkan hafalan dan pemahaman siswa pada pembelajaran Tahfiz di MI Nurul Qomar Palembang digunakan tes lisan hafalan dan pemahaman surat At-Takwir ayat 1-10 sebagai instrumen tes. Tes dilaksanakan langsung dengan siswa praktik hafalan dan pemahaman surat At-Takwir ayat 1-10 dengan masingmasing 3 instrumen. Sebelum instrumen tes digunakan terlebih dahulu dilakukan uji instrumen, baik uji validitas maupun uji reliabilitas.

Tes diberikan kepada seluruh siswa setelah melaksanakan pembelajaran di kelas kontrol yang tidak menerapkan metode Kauny Quantum Memory maupun kelas eksperimen yang menerapkan metode Kauny Quantum Memory. Adapun rekapitulasi hasil tes hafalan dan pemahaman siswa pada pembelajaran Tahfiz baik pada kelas eksperimen maupun kelas kontrol sebagai berikut :

Tabel 1. Rekapitulasi hasil tes kelas eksperimen dan kelas kontrol

\begin{tabular}{|c|c|c|c|c|c|c|}
\hline \multirow[t]{2}{*}{ No } & \multirow[t]{2}{*}{ Interval } & \multirow{2}{*}{$\begin{array}{l}\text { Kategori } \\
\text { rangking }\end{array}$} & \multicolumn{2}{|c|}{$\begin{array}{c}\text { Metode Konvensional } \\
\text { (Kontrol) }\end{array}$} & \multicolumn{2}{|c|}{$\begin{array}{c}\text { Metode Kauny Quantum } \\
\text { Memory } \\
\text { (Eksperimen) }\end{array}$} \\
\hline & & & $\begin{array}{c}\text { Jumlah } \\
\text { Siswa }\end{array}$ & Presentase & $\begin{array}{c}\text { Jumlah } \\
\text { Siswa } \\
\end{array}$ & Presentase \\
\hline 1 & $>82,75$ & Atas & 0 & $0,00 \%$ & 7 & $32 \%$ \\
\hline 2 & 82,75 s.d 68,25 & Tengah & 15 & $75 \%$ & 14 & $64 \%$ \\
\hline \multirow[t]{2}{*}{3} & $<68,25$ & Bawah & 5 & $25 \%$ & 1 & $4 \%$ \\
\hline & & & $\mathrm{N}=20$ & $100 \%$ & $\mathrm{~N}=22$ & $100 \%$ \\
\hline
\end{tabular}

Berdasarkan hasil uji t diperoleh harga $t_{\text {hitung }}$ sebesar $=4,112$, jika dikonsultasikan dengan harga kritik t pada taraf signifikan $5 \%$ dengan $\mathrm{db}=\mathrm{n}-2(22-2=20)$ diperoleh harga $t_{\text {tabel }}=2,09$. Data tersebut menunjukkan bahwa $t_{\text {hitung }}>t_{\text {tabel }}$ atau 4,112 $>2,09$. Karena $t_{\text {hitung }}=4,112$ lebih besar daripada harga $t_{\text {tabel }}=2,09$ pada taraf signifikan $5 \%$ dengan derajat kebebasan n-2 $(22-2=20)$, maka $H_{o}$ yang menyatakan tidak terdapat pengaruh signifikan dengan penerapan metode Kauny Quantum Memory dalam meningkatkan hafalan dan pemahaman siswa pada pembelajaran Tahfiz di MI Nurul Qomar Palembang ditolak, sedangkan $H_{a}$ yang menyatakan terdapat pengaruh signifikan dengan penerapan metode Kauny Quantum Memory dalam meningkatkan hafalan dan pemahaman siswa pada pembelajaran Tahfiz di MI Nurul Qomar Palembang diterima.

Oleh karena itu dapat dikatakan bahwa secara nyata terdapat pengaruh penerapan metode Kauny Quantum Memory yang signifikan dalam meningkatkan hafalan dan pemahaman siswa pada pembelajaran Tahfiz di MI Nurul Qomar Palembang. Dengan kata lain siswa yang pembelajarannya menerapkan metode Kauny Quantum Memory hasil tesnya lebih tinggi daripada siswa yang pembelajarannya tidak diterapkan metode Kauny Quantum Memory. Hal ini terbukti dari tabel persentase yang menunjukkan bahwa pada kelompok siswa yang pembelajarannya menerapkan metode Kauny Quantum Memory terdapat 7 siswa $(32 \%)$ berada pada rangking atas, sedangkan tidak terdapat satu orang siswa pun mendapat 
rangking atas pada kelompok siswa yang pembelajarannya tidak diterapkan metode Kauny Quantum Memory atau pembelajaran Tahfiz dilaksanakan seperti biasanya.

Selama proses pelaksanaan metode pembelajaran Kauny Quantum Memory terlihat siswa merasa tidak ada bosan atau bingung, siswa semakin semangat dengan mengikuti gerakan-gerakan yang berkaitan dengan ayat-ayat Al-Qur'an yang akan di hafal. Di kelas eksperimen terjadi proses pembelajaran yang efektif dan interaksi yang terjadi antar siswa yang diikuti dengan canda tawa sesama siswa. Tetapi hal ini tidak menyurutkan siswa untuk terus melakukan proses pembelajaran dengan metode Kauny Quantum Memory yang kadangkala mengalami kendala dalam mengikuti gerakan yang dicontohkan. Tetapi peneliti langsung membimbing siswa dengan mempraktekkan gerakan yang sesuai.

\section{KESIMPULAN}

Dalam proses pelaksanaan pembelajaran, pendidik harus mampu mengetahui situasi dan kondisi kelas yang akan berlangsungnya proses pembelajaran. Berbagai komponen yang perlu dipersiapkan pendidik sebelum menghadapi peserta didik. Salah satunya dengan menentukan metode pembelajaran yang cocok untuk peserta didik dengan mempertimbangkan situasi dan kondisi kelas. Metode Kauny Quantum Memory terbukti efektif menjadi salah satu metode pembelajaran yang digunakan dalam pelaksanaan penelitian dengan judul penerapan metode Kauny Quantum Memory dalam meningkatkan hafalan dan pemahaman siswa pada pembelajaran Tahfiz di MI Nurul Qomar Palembang.

Dalam penelitian ini yang menjadi objek penelitian adalah siswa MI Nurul Qomar Palembang kelas VI yang terdiri dari kelas VIA sebagai eksperimen dan kelas VIB sebagai kelas kontrol. Hafalan dan Pemahaman siswa meningkat setelah menggunakan metode Kauny Quantum Memory. Metode Kauny Quantum Memory adalah salah satu metode menghafal yang asyik dan menyenangkan bagi siswa sehingga siswa lebih mudah dalam menghafal AlQur'an. Terutama teknik visualisasi dengan gerakan tangan dalam metode Kauny Quantum Memory yang menggerakkan seluruh badan dalam proses menghafal siswa. Sesuai dengan perkembangan siswa SD/MI yang berpusat pada psikomotorik (gerak) sehingga membuat siswa lebih mudah dalam menghafal.

Setelah dilaksanakannya penerapan metode Kauny Quantum Memory siswa merasa semangat dan senang dalam menghafal sehingga mereka aktif dalam proses pembelajaran. Selain itu metode Kauny Quantum Memory dapat meningkatkan kemampuan mengingat (memory) dalam menghafal. Sehingga dengan adanya metode Kauny Quantum Memory diharapkan mampu menjadi referensi guru melaksanakan pembelajaran di kelas.

\section{REFERENSI}

Al-Hafidz, A. W. (1994). Bimbingan Praktis Menghafal Al-Qur'an. Jakarta: Bumi Aksara.

Abidin, Z. A. (2016). Metode Cepat Menghafal Juz 'Amma. Yogyakarta: Mahabbah.

Sulaeman, D. Y. (2007). Mukjizat Abad 20 Wonderful Profile Of Husein Tabataba'I.

Bandung: Pustaka IIMaN.

Nazarudin. (2013). Manajemen Pembelajaran. Yogyakarta: Pustaka Felicha.

Sa'dulloh. (2008). 9 Cara Praktis Menghafal Al-Qur'an. Jakarta: Gema Insani Press.

Emzir, (2014). Metodologi Penelitian dan Pengembangan. Depok: PT. Raja Grafindo Persada.

Sukmadinata, N. S. (2013). Metode Penelitian Pendidikan. Bandung: Remaja Rosda Karya. 